\title{
A rare case of conjoined twins: craniothoraco omphalopagus-non janiceps
}

\section{Thulasi Devi, Gurusamy Prasad*}

Department of Obstetrics and Gynaecology, Military Hospital, Thiruvananthapuram, Kerala, India

Received: 17 March 2021

Accepted: 14 April 2021

\section{*Correspondence:}

Dr. Gurusamy Prasad,

E-mail: mgrprasad7@gmail.com

Copyright: (c) the author(s), publisher and licensee Medip Academy. This is an open-access article distributed under the terms of the Creative Commons Attribution Non-Commercial License, which permits unrestricted non-commercial use, distribution, and reproduction in any medium, provided the original work is properly cited.

\begin{abstract}
A very rare case of conjoined twins, incompatible with life. Craniothoraco omphalopagus terminated after second trimester anomalies scan. Only anecdotal case reports were available and their inheritance pattern remains a mystery. They were inoperable. Here we present such a case which was unbooked and unregistered and escaped detection till late second trimester due to non-availability of maternity services. These cases if they reached term had to be delivered always by classical caesarean due to obstructed labour and difficulty in delivery via LUS due to variety of difficulties and manoeuvrability by obstetrician. LSCS should not be attempted as it invariably leads to an inverted T scar on the uterus with increased blood loss. A classical caesarean section always leads to increased risk of future rupture and spoils the obstetric career of the woman. These cases if detected early can be delivered vaginally with ease by an experienced consultant.
\end{abstract}

Keywords: Conjoined twins, Non janiceps, Lethal malformation

\section{INTRODUCTION}

Conjoined twins are rare in twin pregnancy and craniothoraco omphalopagus-non janiceps also referred to as cephalopagus-non janiceps is an extremely rare variant with limited cases reported till date. ${ }^{1,2}$ These variants of twins are fused at their head, thorax and upper abdominal cavities and are of two types; janiceps (two faces are on the either side of the head) or non janiceps type (with a relatively normal single head and face). We present a case of non janiceps type variant of conjoined twins. The twins had a single head, apparently normal single face, four upper limbs and four lower limbs. The male twins were joined with their head, thorax and upper abdominal cavity. On ultrasound examination (done after delivery), the twins had two separate lungs and a single heart. The genitourinary system was unremarkable. This malformation not detected pregnancy as the patient had no prior antenatal visits. These twins were still born. Next of kin refused for autopsy inspite of extensive counselling by paediatrician for better understanding of this extremely rare variant. An early prenatal diagnosis can be made by USG at 12 weeks gestation, it was missed in this case and hence could not be terminated. Surgery is not attempted in these cases as they are considered inoperable.

\section{CASE REPORT}

A 27 years old, $\mathrm{G}_{3} \mathrm{P}_{2} \mathrm{~L}_{2}$ lady with previous two spontaneous vaginal delivery by midwife without any intrapartum and postpartum complications presented to us in labour as unbooked, unregistered case, spontaneous conception with no history of consanguinity, exposure to drugs, vaccines or radiation at POG 29-30 weeks with a radiological diagnosis of conjoined twins (USG and MRI done). This was her first USG. A diagnosis of craniothoraco omphalopagus-non janiceps was already made by consultant radiologist. She was already aware of the outcome and had reported to our centre for termination as it was refused by midwife and gynaecologist at PHC due to lack of blood bank and OT 
facilities. She was in advanced labour with good uterine contractions, approximately $60 \%$ effaced, 6-7 cm dilated, membranes were present and bulging and was augmented with oxytocin. She delivered still born male conjoined twins with assisted cephalic delivery uneventfully (Figure 1-6). Placenta and membranes were delivered in toto and her postpartum period was uneventful.

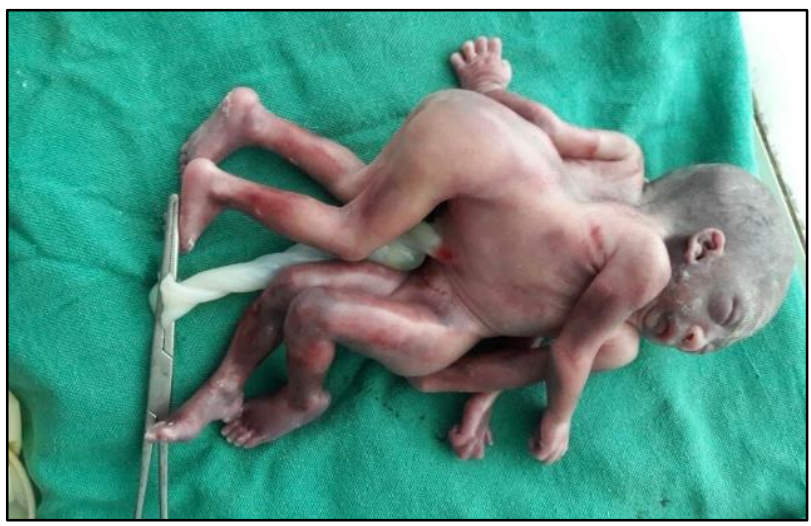

Figure 1: Lateral view of conjoined twins, still born at birth.

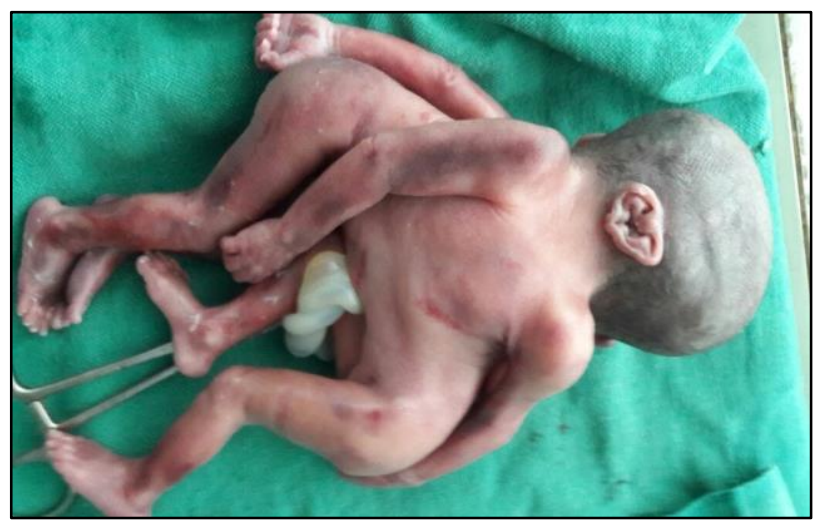

Figure 2: Posterior view of head showing two occipital protuberances.

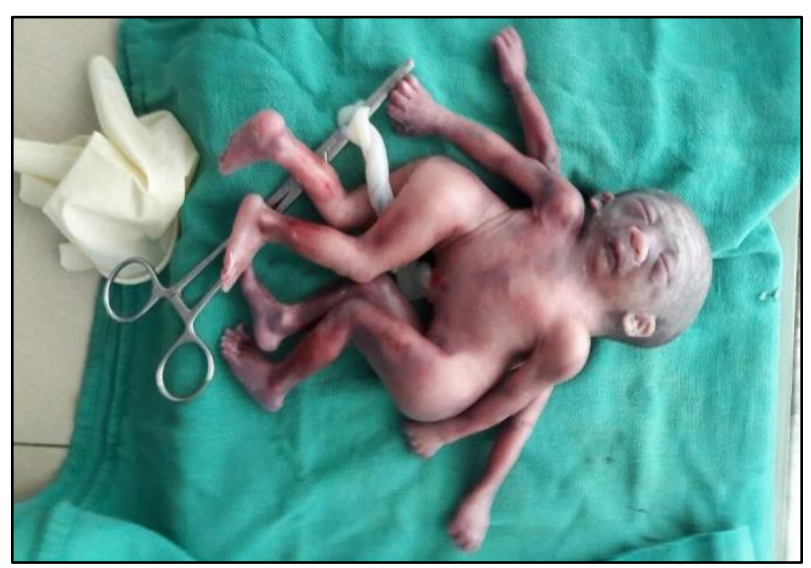

Figure 3: Anterior view conjoined twins, cephalopagus-non janiceps.

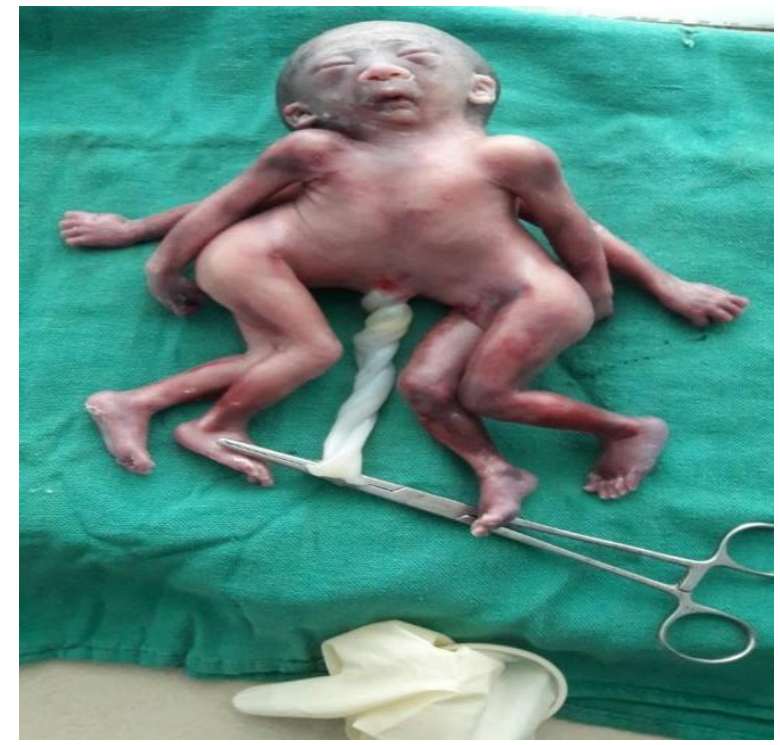

Figure 4: Craniopagus; fused at skull, thorax, abdomen, four upper limbs and four lower limbs with a single face; note single umbilical cord.

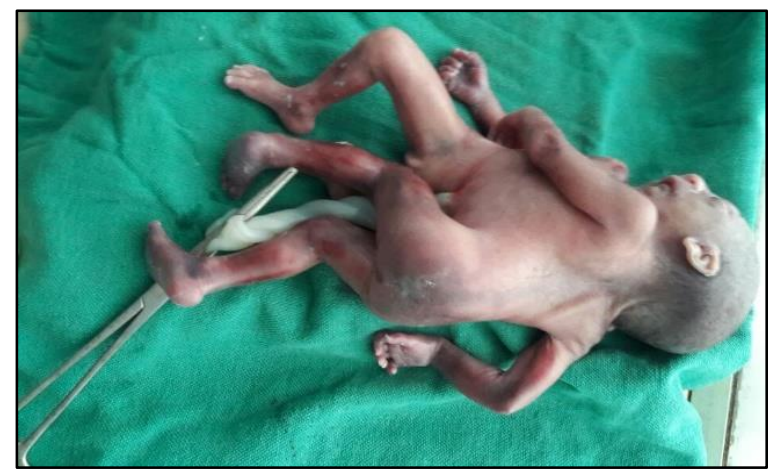

Figure 5: Note sex of the twins (male).

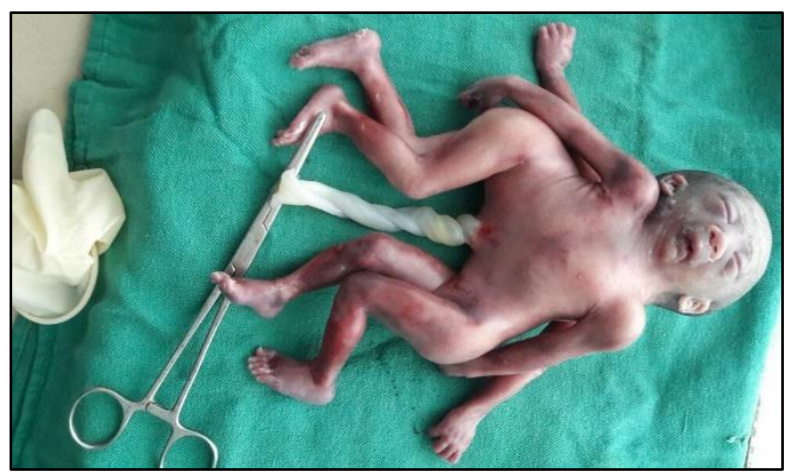

Figure 6: Conjoined twins with only two nipples.

\section{DISCUSSION}

Conjoined twining is an uncommon complication of monozygotic twinning. Among all the monozygotic twin pregnancies, it has an estimated incidence of $1 \%$. It is believed that this malformation occurs predominantly in 
females, with a ratio of 3:1 but their incidence does not vary with maternal age or parity. The first documented case of conjoined twins that of Biddenden maids in 1100 AD. ${ }^{3}$ There are several varieties of conjoined twins and these are classified based on different classification systems. The embryonic classification of conjoined twins by Spencer classifies them into eight types based on the extent and location of fusion. The most common type in this classification include thoracopagus, omphalopagus and thoraco-omphalopagus; all accounting for $56 \%$ conjoined twins. ${ }^{4}$ The simplified classification of the eight types of conjoined twins proposed by Rowena Spencer herein employs terminology commonly found in the current literature, logically organized and with specific restrictions (Figure 7 and 8 ). ${ }^{4,5}$ Further reading is advised and recent review of literature may be referred for additional changes and classification. There are no uniform guidelines recommended for their classification as prenatal diagnosis of this condition has improved and pregnancy is invariably terminated. Further research, etiopathogenesis, along with inheritance pattern is required for better understanding of these disorders. RCT and prospective trials cannot be done for these conditions as a rule as ethical approval will not be granted. All studies and understanding are dependent on retrospective case studies and anecdotal reports. The thorax is always united in cephalopagus twins, cephalothoracopagus is redundant and should not be used.

\section{VENTRAL CONJUNCTIONS}

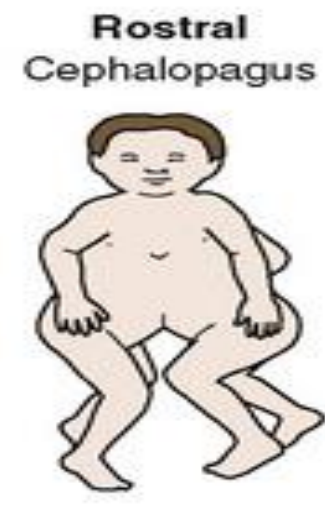

Caudal Ischiopagus

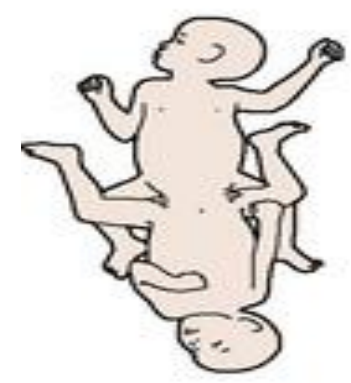

Craniopagus

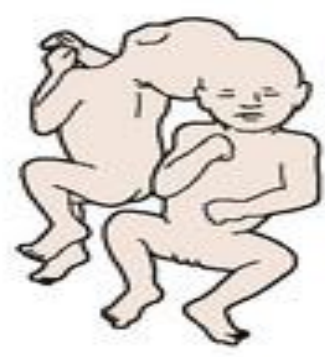

Thoracopagus

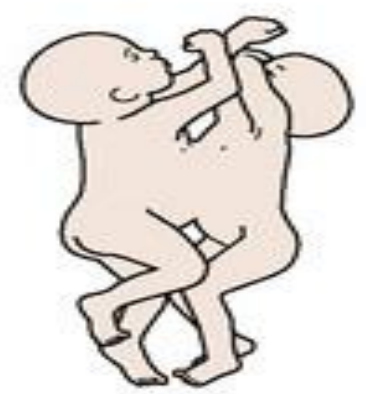

Omphalopagus

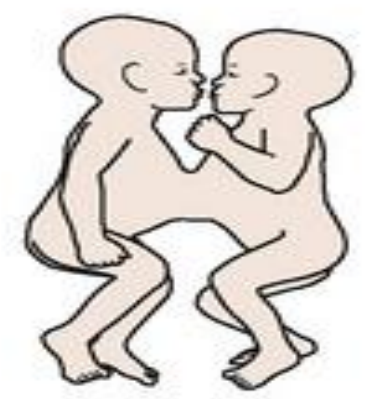

Lateral

Parapagus diprosopus Parapagus dicephalus

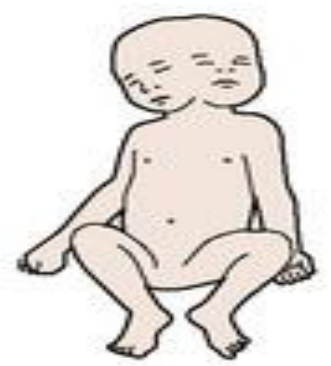

\section{DORSAL CONJUNCTIONS}
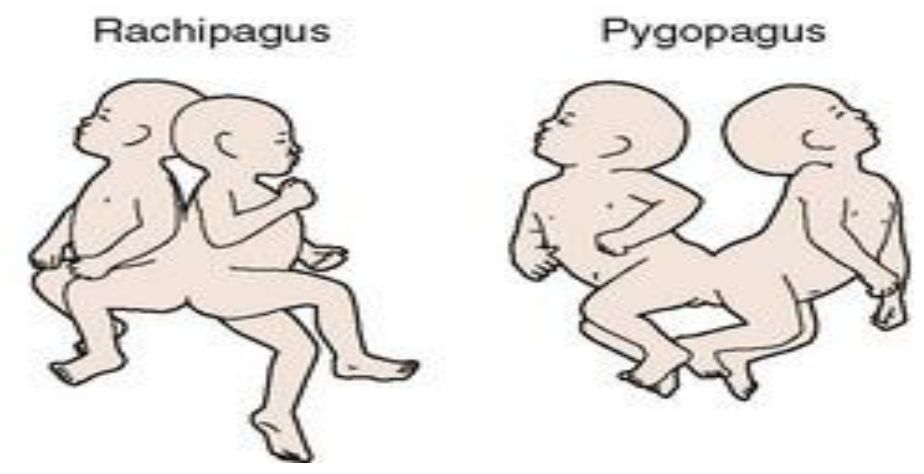

Figure 7: Classification suggested by Rowena Spencer. 


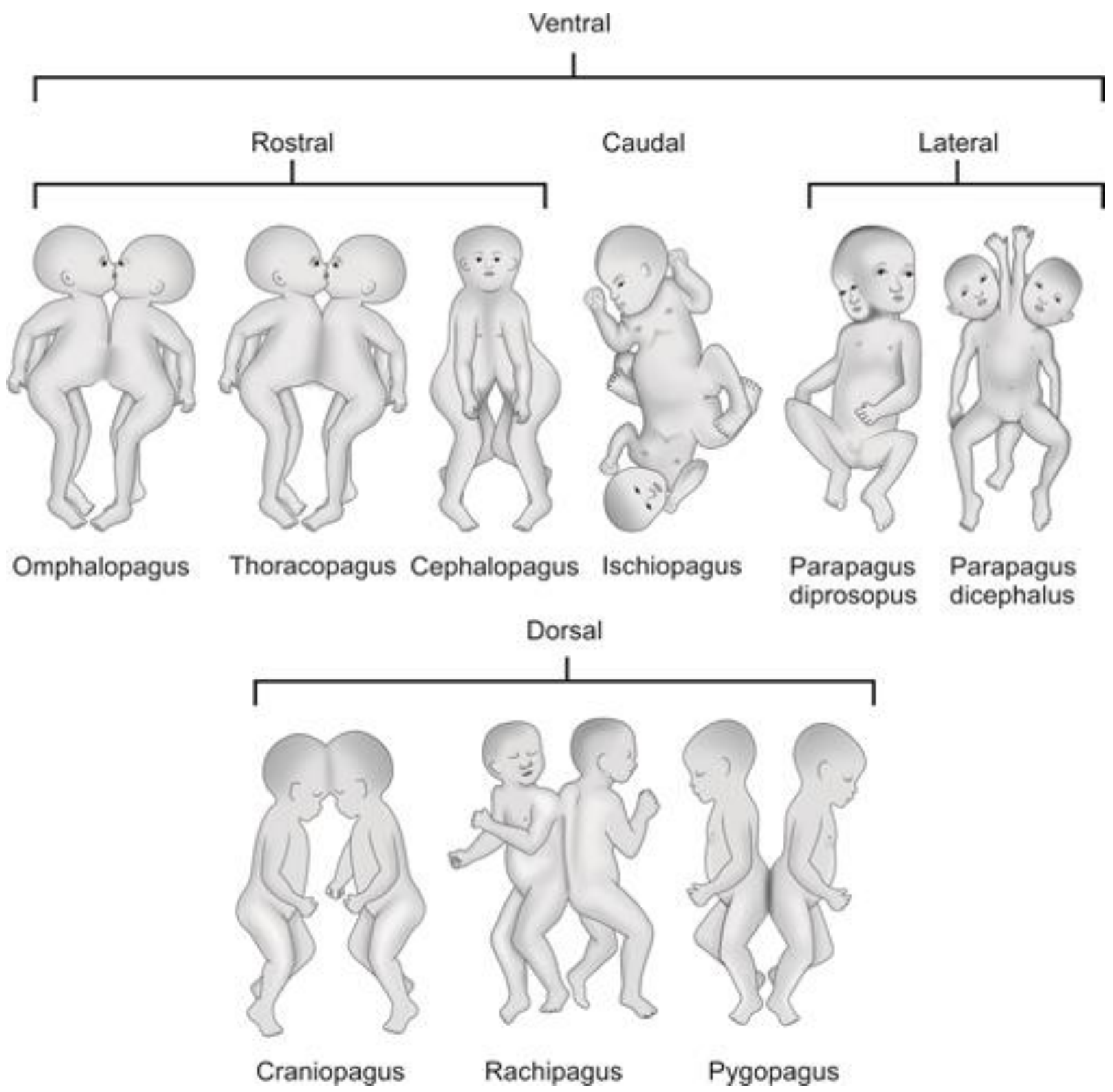

Figure 8: Classification suggested by Agarwal S and Kore S.

Cephalopagus is the rarest variety of conjoined twins, accounting for about $11 \%$ of all conjoined twins. The twins in this disorder are fused in their head, thoracic and upper abdominal cavities. Cephalopagus twins are of two types, janiceps (two faces are on the either side of the head) or non janiceps (with a relatively normal head and face). ${ }^{6}$ Two protuberances were seen in the occipital region (Figure 2).

The precise etiology of conjoined twinning is unknown. The most common explanation is fission of single zygote, or fusion of two dizygotic or monozygotic embryos in their very early embryonic development between 13 and 15 days after conception. Since conjoined twins develop after differentiation of the chorion and amnion all conjoined twins are monoamniotic and monochorionic. ${ }^{7,8}$

\section{CONCLUSION}

Available literature and data show that non-janiceps type of cephalopagus twins are extremely rare variety of conjoined twins with fused head, thorax and upper abdominal wall. The lower abdomen and pelvic cavities are free. There are four upper limbs and four lower limbs. This variant of conjoined twins is non-viable and incompatible with life due to malformations of the brain and the spinal cord. Hence, surgical intervention is not attempted as they are inoperable. Autopsies of such fetal congenital malformations can be very helpful in understanding the unique anatomic arrangement found in them which can possibly shed highlight on mechanisms of embryology and in better understanding of etiopathogenesis of such cases. 
Funding: No funding sources

Conflict of interest: None declared

Ethical approval: Not required

\section{REFERENCES}

1. Vural F, Vural B. First trimester diagnosis of dicephalic parapagus conjoined twins via transvaginal ultrasonography. J Clin Ultrasound. 2005;33(7):364-6.

2. Turgut F, Turgut M, Başaloglu H, Başaloglu HK, Haberal A. Extremely rare type of conjoined twins: cephalothoracopagusderadelphus. Eur J Obstet Gynecol Reprod Biol. 1998;80(2):191-4.

3. Bondeson J. The Biddenden maids: a curious chapter in the history of conjoined twins. J R Soc Med. 1992;85(4):217-21.

4. Spencer R. Anatomic description of conjoined twins: a plea for standardized terminology. J Pediatr Surg. 1996;31(7):941-4.
5. Agarwal S, Kore S. Multiple Gestations: Basics and Beyond. $1^{\text {st }}$ ed. India: Jaypee Brothers Medical Publishers; 2017.

6. Chen CP, Lee CC, Liu FF, Jan SW, Lin MH, Chen BF. Prenatal diagnosis of cephalothoracopagus janiceps monosymmetros. Prenat Diagn. 1997;17(4):384-8.

7. Graham GM, Gaddipati S. Diagnosis and management of obstetrical complications unique to multiple gestations. Semin Perinatol. 2005;29(5):282-95.

8. Stone JL, Goodrich JT. The craniopagus malformation: Classification and implications for surgical separation. Brain. 2006;129:1084-95.

Cite this article as: Devi LT, Prasad G. A rare case of conjoined twins: craniothoraco omphalopagus-non janiceps. Int J Reprod Contracept Obstet Gynecol 2021;10:2110-4. 